\title{
Dengue Outbreak in Children During 2019: Experience at A Tertiary Care teaching Hospital
}

\author{
Mitra Datta ${ }^{1 *}$ \\ Asma Ferdousi ${ }^{1}$ \\ Salina Haque ${ }^{1}$ \\ Rifat Jahan' \\ Aparup Das ${ }^{1}$ \\ Tanjina $\mathrm{Haq}^{2}$
}

'Department of Pediatrics Chittagong Medical College Chattogram, Bangladesh.

${ }^{2}$ Bangladesh Institute of Tropical Infectious Disease (BITID)

Chattogram, Bangladesh.
*Correspondence to:

Dr. Mitra Datta

Assistant Professor

Department of Pediatric

Chittagong Medical College

Chattogram, Bangladesh.

Mobile : +8801812510063

Email:mitradatta71@gmail.com

Date of Submission : 16.11 .2020

Date of Acceptance : $\quad 20.12 .2021$

www.banglajol.info/index.php/CMOSHMCJ

\begin{abstract}
Background: Dengue outbreaks are hitting different geographic locations, different clinical manifestations are being reported recently. This study was aimed to describe the clinico-epidemiological profile and outcome of dengue infected children during 2019 dengue outbreak in Chattogram.
\end{abstract}

Materials and methods: This hospital based prospective observational study was carried out in the Department of Pediatrics in Chattogram Medical College Hospital. Serologically positive dengue cases (Aged $\leq 12$ years) admitted from July 2019 to December 2019 were enrolled in the study. Hospital outcome of the patient's was recorded in terms of mortality, Length of Hospital Stay (LOS) need for ICU.

Results: Out of total 192 patients as per the National Guideline 66.7\% cases were classified as dengue fever without warning signs, $21.9 \%$ as dengue fever with warning signs and $11.5 \%$ as severe dengue. Overall the mean age was $7.04( \pm 3.23)$ years with male preponderance (59\%). Along with fever main complaints were abdominal pain (91.7\%), vomiting (47.9\%) and headache (23.6\%). Marked thrombocytopenia (Below 50,000) was present in $37.9 \%$, leucopenia in $27.9 \%$ and raised haematocrit in 10.9\% of cases. Average LOS was 5.2 ( \pm 1.9$)$ days, 18 (9.5\%) patients need ICU admission and there was no fatality in this series. Some clinical (Vomiting, flusihing, shock, reduced urinary output) and laboratory (Marked thrombocytopenia, leucopenia, hemoconcentration, pleural effusion and hepatomegaly) variables were associated with severity.

Conclusion: Fever with abdominal pain were common presentations of dengue fever. Severe dengue patients presented with vomiting, flashing and shock. Marked thrombocytopenia and pleural effusion and/or ascites were related to shock. Appropriate and timely management is very effective in reducing case fatality.

Key words: Dengue fever; Severe dengue; Febrile viral disease; Aedes mosquitoes.

\section{INTRODUCTION}

Dengue fever is an acute febrile viral disease transmitted by the bite of Aedes mosquitoes carrying any one of the four dengue viral serotypes. Approximately half of the world's population is at risk, especially people residing in tropical and subtropical climates such as in Bangladesh. About 390 million dengue infections are estimated to occur annually, of which a quarter of the cases (67-136 million) will manifest clinically, with the overall incidence of dengue having increased 30 -fold over the past 50 years ${ }^{1,2}$.

In Bangladesh, the first epidemic of dengue hemorrhagic fever occurred in mid-2000 when 5,551 dengue infections were reported from Dhaka, Chittagong, and Khulna cities, occurring mainly among adults ${ }^{3}$. From then onwards, dengue outbreaks have occurred in small or large scales every year in Bangladesh ${ }^{4-7}$. In the year 2019 Bangladesh has experienced an unprecedented dengue outbreak that has resulted in an enormous increase in the number of cases and mortality as compared to previous years ${ }^{8}$. 
Regular reporting of the clinic-epidemiolgical profile is an essential element for successful prevention and control of infectious disease. Considering a public health threat this type of reporting are on going from different parts of the world ${ }^{9-11}$. Despite large number of cases being reported every year in Bangladesh, alarmingly not much of literature is available on clinic-epidemiological profile of cases of DF, especially from pediatric age group ${ }^{12-13}$. The present study was aimed to highlight the clinico-pathological presentation and outcome of paediatric dengue cases encountered in the 2019 outbreak in a tertiary care hospital in Chattogram, Bangladesh.

\section{MATERIALS AND METHODS}

This prospective observational study was carried out from July to December 2019 in Chittagong Medical College Hospital $(\mathrm{CMCH}) 2^{\text {nd }}$ largest tertiary care hospital of Bangladesh. A total 192 infant and children, aged 0-12 years admitted during this time with a confirmed diagnosis of DF (Positive to Dengue NS1 antigen and/or anti-dengue IgM antibodies) were included in the study. Patients with concomitant malaria and typhoid were excluded. Prior approval was taken from the Ethical Review Committee of CMC and informed consent was obtained from the guardian of the patient.

Detailed history was taken and clinical examination was performed on admission and subsequently during the stay in the hospital. Dengue cases were classified according National Guideline 2018 classification. The laboratory investigations like complete blood count including- hemoglobin level, Platelet count and PCV, was done in all the cases and repeated. Chest $\mathrm{X}$-ray, ultrasonography of the abdomen and chest, Liver and renal function tests were done when needed. These patients were managed according to national guideline ${ }^{14}$. Patients were discharged from hospital when fever subsided and/or vital signs became normal.

Data were expressed as frequencies, means, and standard deviations. To determine the factors associated with severe dengue, chi-square tests were used for categorical variables and student's t-tests were used for continuous variables. Data were analyzed with SPSS-23. $p$ value $<0.05$ was considered as statisticaly significant.

\section{RESULTS}

According to National Guideline 2018 classification, out of 192 patients majority of them were presented as dengue fever without any warning sign $(66.7 \%, 128 / 192)$, followed by $21.9 \%(42 / 192)$ patients presented as dengue with warning sign and $11.4 \%$ children (22/192) with severe dengue who presented with shock (Figure 1). For further analysis patients were categorized in two groups: non severe $\mathrm{DF}(\mathrm{n}=170)$ and severe DF $(n=22)$.

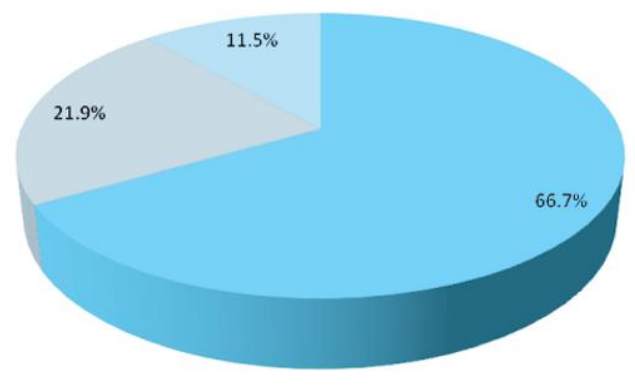

= DF without warning sign $=$ DF with warning sign $=$ DSS

Figure 1: WHO classification of the patients $(n=192)$.

Overall mean age of the patients were $7.04( \pm 3.23)$ years. Male female ratio was $1: 0.7$. Twenty $(10.4 \%)$ of the patients were referred from the Hill Tracks. There was no significant difference in mean age and sex distribution between non severe and sever cases (Table I).

Table I : Demographic characteristics of the patients $(n=192)$.

\begin{tabular}{|c|c|c|c|c|}
\hline Variables & $\begin{array}{r}\text { Total } \\
(\mathrm{n}=192)\end{array}$ & $\begin{array}{l}\text { Non severe } \\
\text { DF }(n=170)\end{array}$ & $\begin{array}{l}\text { Severe } \\
(\mathrm{n}=22)\end{array}$ & $p$ value \\
\hline \multicolumn{5}{|l|}{ Age (Years) } \\
\hline Mean \pm SD & $7.04 \pm 3.23$ & $7.10 \pm 3.29$ & $6.57 \pm 2.74$ & \multirow[t]{2}{*}{$0.466^{\mathrm{NS}}$} \\
\hline Range & $0.50-1.20$ & $0.50-12.00$ & $1.00-12.00$ & \\
\hline \multicolumn{5}{|l|}{ Sex } \\
\hline Male & $114(59.4)$ & $99(58.2)$ & $15(68.2)$ & \multirow[t]{2}{*}{$0.371^{\mathrm{NS}}$} \\
\hline Female & $78(40.6)$ & $71(41.8)$ & $7(31.8)$ & \\
\hline \multicolumn{5}{|l|}{ Residence } \\
\hline Urban & $127(66.2)$ & $108(63.5)$ & $19(86.4)$ & \multirow{3}{*}{$0.022^{\mathrm{S}}$} \\
\hline Rural & $45(23.4)$ & $45(26.5)$ & $0(0)$ & \\
\hline Hill tracks & $20(10.4)$ & $17(10.0)$ & $3(13.6)$ & \\
\hline
\end{tabular}

Data are expressed as frequency (Percentage) if not mentioned otherwise. S: Significant statistically, NS: Statistically not significant.

The most common clinical manifestation was fever followed by abdominal pain, vomiting, headache, artharliga/myalgia. Some features like vomiting, flushing, shock, reduced urine output and respiratory distress were observed significantly more in patients with severe dengue compared to non severe dengue (Table II).

Table II: clinical features of the patients $(n=192)$.

\begin{tabular}{lrrrr} 
Clinical features $^{*}$ & $\begin{array}{r}\text { Total } \\
(\mathbf{n}=\mathbf{1 9 2})\end{array}$ & $\mathbf{D F}(\mathbf{n}=\mathbf{1 7 0})$ & $\begin{array}{r}\text { Severe } \\
(\mathbf{n}=\mathbf{2 2})\end{array}$ & p value \\
\hline Fever & $192(100)$ & $170(100)$ & $22(100)$ & $\mathrm{NA}$ \\
Abdominal pain & $176(91.7)$ & $154(90.6)$ & $22(100)$ & $0.133^{\mathrm{NS}}$ \\
Vomiting & $92(47.9)$ & $71(42.0)$ & $21(95.5)$ & $<0.001^{\mathrm{S}}$ \\
Headache & $45(23.6)$ & $39(23.1)$ & $6(27.3)$ & $0.863^{\mathrm{NS}}$ \\
Arthralgia/Myalgia & $28(14.5)$ & $25(14.7)$ & $3(13.6)$ & $0.894^{\mathrm{NS}}$ \\
Flushing & $26(13.5)$ & $14(8.2)$ & $12(54.5)$ & $<0.001^{\mathrm{S}}$ \\
Skin rash & $22(11.4)$ & $17(10.0)$ & $5(22.7)$ & $0.078^{\mathrm{NS}}$ \\
Shock & $18(9.4)$ & $0(0)$ & $22(100)$ & $<0.001^{\mathrm{S}}$ \\
Reduced urine output & $16(8.3)$ & 0() & $16(72.7)$ & $<0.001^{\mathrm{S}}$ \\
Respiratory Distress & $10(5.2)$ & $0(0)$ & $10(45.5)$ & $<0.001^{\mathrm{S}}$ \\
Tourniquet test positive & $10(5.2)$ & $5(2.9)$ & $5(22.7)$ & 0.008
\end{tabular}


* Showing the features present at least in $5 \%$ of the patients. Data are expressed as frequency (Percentage), S: Significant statistically, NS: Statistically not significant, NA: Not applicable.

About $38 \%$ of the patients had platelet count $\leq 100,000 /$ cc . $64.4 \%$ of cases had normal leukocyte count, while leukopenia was seen in $27.4 \%$ and leucocytosis in $8.2 \%$ of cases. In this series, hematocrit $>40$ was observed in $10.9 \%$ patients (Table III). Sonographic findings of fluid accumulation like pleural effusion and ascites were significantly more observed in severe cases compared to non severe cases.

Table III: Clinical features and laboratory parameters of the patients $(n=192)$.

\begin{tabular}{|c|c|c|c|c|}
\hline Parameters & $\begin{array}{r}\text { Total } \\
(\mathrm{n}=192)\end{array}$ & $\begin{array}{l}\text { Non severe } \\
\text { DF }(n=170)\end{array}$ & $\begin{array}{l}\text { Severe } \\
(n=22)\end{array}$ & $\mathrm{p}$ value \\
\hline \multicolumn{5}{|l|}{ Hemoglobin, gm/dl } \\
\hline Mean \pm SD & $12.01 \pm 1.88$ & $11.98 \pm 1.17$ & $12.34 \pm 1.59$ & $0.263^{\mathrm{NS}}$ \\
\hline \multicolumn{5}{|l|}{ Platelet count } \\
\hline$>1,50,000$ & $53(27.7)$ & $53(31.2)$ & $0(0)$ & \\
\hline $1,00,000-1,50,000$ & $66(34.3)$ & $63(37.1)$ & $3(13.6)$ & \\
\hline $50,000-1,00,000$ & $36(18.7)$ & $32(18.8)$ & $4(182)$ & $<0.001^{\mathrm{S}}$ \\
\hline $20,000-50,000$ & $31(16.1)$ & $22(18.8)$ & $9(40.9)$ & \\
\hline$<20,000$ & $6(3.1)$ & $0(0)$ & $6(27.3)$ & \\
\hline \multicolumn{5}{|l|}{ WBC count } \\
\hline$<4000 / \mathrm{cc}$ & $52(27.4)$ & $36(21.2)$ & $16(72.7)$ & \\
\hline $4000-11000 / \mathrm{cc}$ & $124(64.4)$ & $120(70.6)$ & $4(18.2)$ & $<0.001^{\mathrm{S}}$ \\
\hline$>11000 / \mathrm{cc}$ & $16(8.2)$ & $14(8.2)$ & $2(9.1)$ & \\
\hline \multicolumn{5}{|l|}{ Hematocrit (L/L) } \\
\hline$\geq 40$ & $21(10.9)$ & $13(7.6)$ & $8(36.4)$ & \\
\hline $30-40$ & $163(84.9)$ & $152(89.4)$ & $11(50.0)$ & $<0.001^{\mathrm{S}}$ \\
\hline$<30$ & $8(4.2)$ & $5(2.9)$ & $3(13.6)$ & \\
\hline \multicolumn{5}{|l|}{ USG findings } \\
\hline Unilateral PE & $24(12.5)$ & $16(9.4)$ & $8(36.4)$ & $<0.001 \mathrm{~S}$ \\
\hline Bilateral PE & $12(6.3)$ & $2(1.2)$ & $10(45.5)$ & $<0.001 \mathrm{~s}$ \\
\hline Ascites & $46(24.0)$ & $30(17.6)$ & $16(72.7)$ & $<0.001 \mathrm{~s}$ \\
\hline Hepatomegaly & $10(5.2)$ & $5(2.9)$ & $5(22.7)$ & $<0.001 \mathrm{~s}$ \\
\hline Spleenomagely & $7(3.6)$ & $2(1.2)$ & $5(22.7)$ & $<0.001^{\mathrm{S}}$ \\
\hline GB oedema & $10(5.2)$ & $2(1.2)$ & $8(36.4)$ & $<0.001^{\mathrm{S}}$ \\
\hline
\end{tabular}

Data are expressed as frequency (Percentage) if not otherwise mentioned, S: Significant statistically, NS: Statistically not significant.

Mean duration of hospital stay was $5.2 \pm 1.9$ days. 18 patients needed ICU management. All the 192 patients were recovered and discharged (Table IV). As expected, LOS and ICU admission requirement were significantly higher for severe cases compared to non severe cases.

Table IV: Outcome pattern of dengue patients $(\mathrm{n}=192)$.

\begin{tabular}{lrrrr} 
Parameters & $\begin{array}{r}\text { Total } \\
(\mathrm{n}=\mathbf{1 9 2})\end{array}$ & $\begin{array}{r}\text { Non severe } \\
\mathbf{D F}(\mathrm{n}=\mathbf{1 7 0})\end{array}$ & $\begin{array}{r}\text { Severe } \\
(\mathbf{n}=\mathbf{2 2})\end{array}$ & p value \\
\hline LOS (Days) & $5.2( \pm 1.9)$ & $4.4( \pm 1.16)$ & $7.0( \pm 1.27)$ & $<0.001^{\mathrm{S}}$ \\
Need for PICU & $18(9.4)$ & $0(0)$ & $18(81.8)$ & $<0.001 \mathrm{~S}$ \\
Mortality & $0(0)$ & $0(0)$ & $0(0)$ & NA \\
\hline
\end{tabular}

Data are expressed as frequency (percentage) or mean $( \pm \mathrm{SD})$, S: Significant statistically, NA: Not applicable, LOS: Length of hospital stay.

\section{DISCUSSION}

Dengue infection is a systemic and dynamic disease. It has a wide clinical spectrum that includes both severe and non-severe clinical manifestations ${ }^{13}$. The current study demonstrated that, mean age was around 7 years which was in agreement with other studies ${ }^{14,15}$. Regarding sex, the current study showed slight male predominance and it was supported by other studies also $^{16,17}$. Reason for dengue being common in older children and in male may be due to more involvement of these children in outdoor activities which might have caused more mosquito bite. Whereas covered dress used by infant and female preventing them from mosquito bite and this may be cause for fewer incidence in infant and female.

Though dengue spread is attributed to the rapid urbanization rural extension was reported by different studies from Bangladesh and India ${ }^{18,19,20}$. It is to be noted that, the current study we observed dengue cases came from both urban and rural areas as well as from hill tracts. Dengue infection may confuse with severe falciparum malaria in a malaria endemic area like Chittagong Hill tract. As in severe falciparum malaria there may be bleeding manifestations and thrombocytopenia ${ }^{21}$.

The majority of the patients were cases of non-severe dengue and only $11.5 \%$ cases were severe dengue. Among the hospitalized patients other studies also reported similar pattern with majority of cases with non-severe dengue infection ${ }^{17}$.

In the present series fever was reported by the entire group. Following fever, abdominal pain was the next common symptom followed by vomiting and headache. Studies showed contrasting results regarding clinical manifestations of dengue infection. Clinical presentations of the patients of the current study were similar to the other recent studies ${ }^{22,23}$. However, earlier study reported higher frequency of rash and flushing, bleeding manifestations ${ }^{20,16}$. In our study, in the majority of the patient's tourniquet test was found to be negative but it had a significant association with severe dengue which was similar to other study conducted in this sub-continent ${ }^{18}$.

There were a low proportion of children with evidence of haemoconcentration in our study group. The percentage increase in haematocrit is an accurate indicator of vascular permeability and plasma leakage. But it was also reported in previous studies that in some cases the fluid leakage does not achieve a high degree haemoconcentration even if the patient is in shock; this explains our findings ${ }^{17,18}$. The present study showed though thrombocytopenia was present in $72.3 \%$ cases and bleeding manifestation in only $3 \%$ cases. But all the patients with shock had platelet count below 50,000/cc and shock was invariably present in children with platelet count $<20,000 /$ cc. This demonstrated that, thrombocytopenia was more relevant to shock than bleeding manifestations. In contrast, other studies observed bleeding manifestation had a significant association with the degree of thrombocytopenia ${ }^{23,24}$. Leukopenia and marked thrombocytopenia was significantly associated with severe dengue which were similar to other results ${ }^{24}$. 
Radiological findings like, unilateral or bilateral pleural effusion, ascites, hepatomegaly, Spleenomagely and gall bladder oedema were more significant in severe dengue. These were in agreement with other studies ${ }^{17,18}$.

The mean tenure of hospitalization was $5.2 \pm 1.9$ days observed in this study which is similar to another study ${ }^{18}$. There was no mortality in the present study. Higher mortality rate was reported by other studies ${ }^{19}$. Similar to other studies early diagnosis and prompt management above all awareness of the disease among the study population were important to minimize or avoid mortality ${ }^{20}$.

\section{LIMITATIONS}

Sample from a single government run tertiary care hospital and limited study period were some of the limiting factors of the current study, which might questioned its generalizability.

\section{CONCLUSIONS}

In an outbreak setting changing clinical spectrum of dengue should be considered for early diagnosis. Distinct features of dengue infection during the 2019 outbreak were expansion of dengue infection among the children of Chittagong Hilltracts.
Post monsoon extension of dengue season. Fever, abdominal pain and vomiting are main features of dengue fever. Severe dengue presented with Shock frequently. Shock was relevant to severity of thrombocytopenia and sonographic changes in abdomen and chest.The entire group had favorable outcome. Early intervention, strict monitoring, ICU facility were probably the reasons for favorable outcome in this study.

\section{RECOMMENDATIONS}

Community awareness regarding symptoms of dengue can help in seeking health care at an early stage and further prevention of progression of disease to late stages, thereby further reducing mortality. Radiological assessment may be helpful to assess the diseases evolution.

\section{DISCLOSURE}

All the authors declared no competing interest. 


\section{REFERENCES}

1. Bhatt S, Gething PW, BradyOJ, Messina JP, Farlow AW, Moyes CL et al. The global distribution and burden of dengue. Nature. 2013; 496(7446):504-507.

2. World Health Organization. Dengue fact sheet. 2019.

Available at: http://www.searo. who.int/entity/ (Accessed Sept 9, 2019).

3. Yunus EB, Mannan BA, Haq MA, Mushfiqur RM, Chowdhury AR, et al. Dengue Outbreak 2000 in Bangladesh: From Speculation to Reality and Exercises. WHO Regional Office for South-East Asia. 2021. https://apps.who.int/iris/handle/10665/163630

4. Pervin M, Tabassum S, Ali MM, Mamun KZ, Islam MN. Clinical and Laboratory Observations associated with the 2000 Dengue Outbreak in Dhaka, Bangladesh. Dengue Bulletin. 2004; 28: 96-106.

5. Sultana N, Biswas SK, Sultan T, Ahmed S, Hossain Z, Chowdhury R. Seroprevalence of dengue fever in Chattogram, Bangladesh. ChattMaa Shi Hosp Med Coll J. 2013;12(1): 38-40.

6. Sharmin R, Tabassum S, Mamun KZ, Nessa A, Jahan M. Dengue infection in Dhaka City, Bangladesh. Mymensing Medical College Journal.2013;22(4): 781-786.

7. Dhar-Chowdhury P, Paul KK, Haque CE, Hossain S, Lindsay LR, Dibernardo A et al. Dengue seroprevalence, seroconversion and risk factors in Dhaka, Bangladesh. PLoSNegl Trop Dis. 2017;11(3):e0005475.

8. Bangladesh Dengue Situation 2019 Health Bulletin - Volume: 3, 10 August, 2019. [Internet] https://reliefweb.int/report/bangladesh/bangladesh-dengue-situation-2019-health-bulletin-volume-2-03-august-2019.

9. Raza FA, Rehman S, Khalid R, Ahmad J, Ashraf S, Iqbal M, Hasnain S. Demographic and Clinico-Epidemiological Features of Dengue Fever in Faisalabad, Pakistan. PLoS ONE. 2014; 9(3): e89868.

10. Rathore MS, Vohra R, Sharma BN, Pankaj JP, Bhardwaj SL, Singh L. Clinico-Epidemiological Study of Dengue in a Tertiary Care Hospital in Jaipur, Rajasthan. Int J Sci Stud 2015;3(9):32-35.

11. Srividya V, Kruthika N. Clinicoepidemiological profile of dengue cases in a medical college hospital, Bengaluru, Karnataka, India. Int J Community Med Public Health 2017;4:928-9232.

12. Mobarak MR, Islam R, Bhuiyan AKMT, Akand N, Begum F. Evaluation of Dengue Fever in A Tertiary Care Children Hospital of Bangladesh. Northern International Medical College Journal. 2017; 9(1):274-277.

13. World Health Organization. Dengue: Guidelines for diagnosis, treatment, prevention and control. Geneva. 2009. Available from: http://www.who.int/tdr/publications/documents/den gue-diagnosis.pdf

14. National Guideline for Clinical Management of Dengue Syndrome. National Malaria Elimination \&Aedes Transmitted Disease Control Program Disease Control Unit Directorate General of Health Services Mohakhali, Dhaka. 2018.

15. Chowdhury PK, Ahmed FU, Das A, Huda N, Chowdhury BM. Dengue and Dengue Haemorrhagic Fever In Children: A Study Of 37 Seropositive Cases In Chittagong. Bangladesh Medical Journal. 2002;31(1\&2):7-8.

16. Ahmed FU, Chowdhury BM, Sharma JD, Hoque SM, Zaman R, Hasan MS. Dengue and Dengue Haemorrhagic Fever In Children During the 2000 Outbreak in Chittagong, Bangladesh: Dengue Bulletin. 2001(25):33-39.

17. Saha KA, Ghosh S. Clinico-Pathological profile in the Infant and Children in Dengue 2012 Epidemic, Kolkata. International journal of Medicine Research \& Health Sciences. 2013;3(1):59-64.

18. Mishra S, Ramanathan R, Agarwalla SK. Clinical profile of dengue fever in children: A study from southern Odisha. India. Scientifica. 2016. Article ID 6391594

http://dx.doi.org/10.1155/2016/6391594

19. Shultana K, Rahman AZMM, Baki A Al, Khan MSI, Deb B, Chowdhury D, Mir ABM R K, Sabrina F, Zaman S, Haque M M. Dengue Infection in Children: Clinical Profile and Outcome in Dhaka City American Journal of Pediatrics 2019;5(3):111-115.

20. Ratageri VH, Shepur TA, Wari PK, Chavan SC, Mujahid IB, Yergolkar PN. Clinical profile and outcome of dengue fever cases. Indian J Pediatr. 2005; 72(8):705-706.

21. Gilles HM. Management of severe and complicated malaria: A practical handbook. Geneva: World Health Organization. 1991:23-24.

22. Majeed IA, Avabratha KS, Gowda LR, Syeda S. Clinicohaematological profile of dengue in children: ahospital based study. Int J ContempPediatr. 2017;4(4):1340-1344.

23. Alam ABM, Sadat S, Swapan Z, Ahmed AU, Karim MN, Paul HK, Zaman S. Clinical Profile of Dengue Fever in Children. Bangladesh J Child Health. 2009;33(2):55-58.

24. Rai S, Bhatia A, Bharmal T, Samant P Rai M. Dengue: A Clinicopathological Correlation. International J Science and Research. 2016;5(10)1978-1981. 